\title{
BMJ Open The Australian public's preferences for emergency care alternatives and the influence of the presenting context: a discrete choice experiment
}

\author{
Paul Harris, ${ }^{1}$ Jennifer A Whitty, ${ }^{2}$ Elizabeth Kendall, ${ }^{3}$ Julie Ratcliffe, ${ }^{4}$
} Andrew Wilson, ${ }^{5}$ Peter Littlejohns, ${ }^{6}$ Paul A Scuffham ${ }^{7}$

To cite: Harris P, Whitty JA, Kendall $\mathrm{E}$, et al. The Australian public's preferences for emergency care alternatives and the influence of the presenting context: a discrete choice experiment. BMJ Open 2015;5:e006820. doi:10.1136/bmjopen-2014006820

- Prepublication history and additional material is available. To view please visit the journal (http://dx.doi.org/ 10.1136/bmjopen-2014006820).

Received 3 October 2014 Revised 5 March 2015 Accepted 6 March 2015

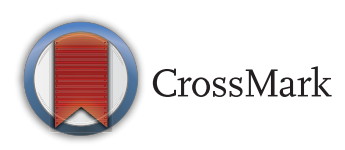

For numbered affiliations see end of article.

Correspondence to

Paul Harris;

p.harris@griffith.edu.au

\section{ABSTRACT}

Objectives: The current study seeks to quantify the Australian public's preferences for emergency care alternatives and determine if preferences differ depending on presenting circumstances.

Setting: Increasing presentations to emergency departments have led to overcrowding, long waiting times and suboptimal health system performance. Accordingly, new service models involving the provision of care in alternative settings and delivered by other practitioners continue to be developed.

Participants: A stratified sample of Australian adults $(n=1838), 1382$ from Queensland and 456 from South Australia, completed the survey. This included 951 females and 887 males from the 2045 people who met the screening criteria out of the 4354 people who accepted the survey invitation.

Interventions: A discrete choice experiment was used to elicit preferences in the context of one of four hypothetical scenarios: a possible concussion, a rash/ asthma-related problem involving oneself or one's child and an anxiety-related presentation. Mixed logit regression was used to analyse the dependent variable choice and identify the relative importance of care attributes and the propensity to access care in each context.

Results: Results indicated a preference for treatment by an emergency physician in hospital for possible concussion and treatment by a doctor in ambulatory settings for rash/asthma-related and anxiety-related problems. Participants were consistently willing to wait longer before making trade-offs in the context of the rash/asthma-related scenario compared with when the same problem affected their child. Results suggest a clear preference for lower costs, shorter wait times and strong emphasis on quality care; however, significant preference heterogeneity was observed.

Conclusions: This study has increased awareness that the public's emergency care choices will differ depending on the presenting context. It has further demonstrated the importance of service quality as a determinant of healthcare choices. The findings have also provided insights into the Australian public's reactions to emergency care reforms.

\section{Strengths and limitations of this study}

- This study represents the first investigation of the Australian public's preferences for emergency care and internationally, the first examination of preferences for both the characteristics of emergency care and service uptake decisions, irrespective of the care options available.

- The demonstration of the importance of contextual factors represents a novel contribution to the literature.

- The results offer some explanations to the apparent inconsistencies in the literature indicating 'inappropriate' presentations to emergency departments even when there are ambulatory alternatives available.

- Although the sample was stratified by age and sex, participants were less diverse and reported higher levels of morbidity compared with the general population.

\section{INTRODUCTION}

Emergency departments (EDs) primarily exist to treat people experiencing medical emergencies, but often provide services to patients with a range of presenting problems of less urgency. ${ }^{1-4}$ Both within Australia and internationally, demand for emergency care has been increasing each year leading to substantial ED pressures. ${ }^{235-7}$ Although the causes of ED overcrowding are complex, sociodemographic changes, including population growth and ageing, and clinical considerations, such as increasing comorbidities, are key contributors to excessive demand. ${ }^{3}$ Other contributing factors relate to system issues, such as decisions about resourcing and the increasing cost of healthcare, ${ }^{89}$ the availability and type of bed stock, and lack of service alternatives. ${ }^{235}$ An additional factor, however, is the public's understanding of ED and when it should be accessed; ${ }^{10}$ 'inappropriate' patient attendance 
is considered to adversely impact the performance of ED. ${ }^{11}$ Despite some conjecture in the literature about the degree to which presentations deemed lower acuity, often referred to as 'GP-type patients', contribute to overcrowding and the utility of alternative service models, ${ }^{3} 1213$ some Australian health authorities have launched social marketing campaigns to redirect the public to alternative care. ${ }^{14}$ Further reforms, including the introduction of user copayments for accessing care, have also been proposed. ${ }^{14} 15$

EDs have been described as being "amongst the biggest 'hotspots' in Australia's healthcare system" (ref 16, p.6). Increasing demand has led to considerable pressures on emergency care resources and staff, overcrowding and 'access block'; with ambulances having to queue to deliver patients and hospitals having to be bypassed due to excessive waiting times. ${ }^{16-18}$ This situation contributes to suboptimal management of critically ill patients and inefficiencies in the health system, ${ }^{3}{ }^{17}$ and has been identified as the most important barrier to the provision of quality care in ED. ${ }^{16}$ Indeed, estimates of the increased mortality rate that can be directly associated with access block and overcrowding in ED range between $10 \%$ and $30 \%$ as a result of the mix of contributing factors identified, in particular, the lack of inpatient beds for people who require hospital admission. ${ }^{3} 16$

In an attempt to address this burden, health decisionmakers, both internationally and in Australia, have sought to understand the way in which the public access ED and under what circumstances. Alternative models of care have been recommended as part of global efforts to manage ED demand, reduce wait times and drive innovation. ${ }^{19}$ Despite recognition of the need to consider contextual issues,${ }^{20}$ there has been limited research on how different presenting problems and contexts may be associated with different patterns of preferences or access to care. Indeed, the public's preferences for emergency care alternatives remain largely unknown. ${ }^{21}$ The results of a recent Hong Kong study suggest that how patients perceive their presentation is key to their care choices. ${ }^{11}$ There are also indications that members of the public understand health emergencies differently to that espoused in clinical guidelines. ${ }^{22}$ This suggests that understanding how patient perceptions influence care choices in different scenarios may provide important insights to drive demand management solutions. However, investigations regarding how different presenting contexts impact preferences for emergency care are limited. ${ }^{11}$

Researchers have begun responding to calls for knowledge about public preferences for emergency care ${ }^{23-25}$ and the impact of different care alternatives on ED presentations. ${ }^{11}{ }^{26}$ However, no previous study has to date explored the impact of different presentations on preferences for the characteristics of care and service uptake decisions. Thus, the current study compared preference patterns of the general public for the delivery of emergency care in the context of different hypothetical scenarios.

\section{METHODS}

A discrete choice experiment (DCE) was developed to elicit the preferences of a representative Australian population sample about the characteristics of an emergency care service and the use of ED in different circumstances. A DCE involves presenting a series of hypothetical scenarios to participants who are asked to indicate their preferred option from a set of mutually exclusive alternatives. ${ }^{27}$ The value of DCE methods in eliciting preferences for emergency care ${ }^{11} 21^{23-25}$ and primary healthcare or alternative settings ${ }^{25}{ }^{28-31}$ has previously been established.

To explore the impact of the presenting context, participants were asked to make their choices in the context of one of four presenting scenarios. The hypothetical scenarios reflected a mix of potentially life-threatening and less-urgent presentations (ie, within the range of emergency care alternatives for which different models of care might potentially exist), and were developed in consultation with health service partners. The primary scenario was designed to represent a typical ED presentation involving injuries from an accident or fall-in this case a possible concussion. In scenario 1 (S1) participants were told to imagine "You have fallen from the top of a ladder and landed heavily. Although you may not have lost consciousness, you hit your head hard and are feeling dazed and nauseous. You are also experiencing pain in your right arm and shoulder and have some cuts and abrasions." The alternative scenarios were designed to represent potential 'GP-type presentations', varying for both the type of concern and person presenting. In scenario 2 (S2), participants were told "You have been diagnosed with asthma. Over the last couple of days you have developed a heavy cough. After showering this morning you noticed you are developing a rash on your upper body which has made you worry about what is going on?" Scenario 3 (S3) included the same presentation involving a rash and possibly an asthma-related problem, but participants were asked to imagine the symptoms that concerned their 12-year-old daughter. These scenarios are, hereafter, referred to as a rash/ asthma-related self (S2) and child (S3). The fourth scenario involved an anxiety related presentation (S4). Participants were asked to imagine being "In distress because your heart won't stop racing. After trying to calm yourself you are still feeling extremely anxious and decide to seek help having previously been diagnosed and treated for anxiety."

A DCE was developed for each scenario in accordance with best practice guidelines. ${ }^{27} 3233$ The DCE presented a series of hypothetical choices between two service models defined by different levels of five key attributes. Attributes of ED care were initially identified through focus group discussions. ${ }^{21}$ Relevant literature was used to refine attribute descriptions and derive attribute levels. $^{24} 2528293134$ Five attributes comprising key features of ED service models were included in the choice scenarios; namely, treating healthcare professional, 
treatment location, waiting time, out-of-pocket cost and service quality.

Levels for treating professionals included being treated by an ED physician, general practitioner (GP) or an emergency care professional other than a doctor, while levels for treatment location were at home, in a local clinic or at hospital. Currently, a vast majority of Australians choose to access an ED at a public hospital with no 'out-of-pocket' expenses as opposed to paying for treatment privately. ${ }^{16}$ Cost levels, therefore, varied from no cost up to a maximum of $\$ 200$ based on the range of out-of-pocket expenses that may be incurred if emergency care were accessed privately. National and international benchmarks designed to reduce overcrowding and excessive wait times were used to set waiting times of half an hour, $1 \mathrm{~h}, 2 \mathrm{~h}$ and a maximum of 4 h. ${ }^{5}{ }^{19}$ Levels for service quality were based on a combination of attribute levels used in related studies, ${ }^{2428} 29$ and ranged from comprehensive care to basic treatment from a clinician who was not easy to understand with some interruptions.

To select pairs of service profiles to be presented to participants, a fractional factorial main effects $\mathrm{D}_{\mathrm{p}}$-efficient design was generated using NGENE software (V.1.1.1, 2012). The combination of attribute levels whereby an emergency care physician treats people in their own homes was considered to be implausible, and was therefore prohibited in the design. ${ }^{27}$ The resulting design generated 24 choice sets, each consisting of a choice between two alternative services (A and B). A blocked design was used to divide the 24 choice sets into a manageable number of 12 choice sets per participant, ${ }^{35}$ with participants randomly allocated to each block. To increase the realism of scenarios, an opt out option was included for each choice set whereby participants could choose to delay accessing care for $24 \mathrm{~h}$ to see if their condition improved. ${ }^{636}$ For each block, one choice set was repeated as a consistency check so as to provide an indication of data quality; however, responses to the repeat choice set were excluded from the preference models. ${ }^{37}$ A sample choice profile is presented in table 1 .

Following ethical approval, ${ }^{21}$ the DCE was pilot tested on a convenience sample of 21 adults. The pilot results were used to make minor amendments and the coefficients generated from analysis of the pilot data were used as prior parameters to improve the efficiency of the experimental design. The survey was then administered via the internet to a sample of adults $(n=1838)$ residing in two Australian States (Queensland (QLD) and South Australia (SA)). Participants were recruited from a survey panel by a third-party provider (PureProfile) between September and December 2012. Quotas were set to ensure the sample reflected the age and gender distribution of the corresponding State populations. All participants were provided with an information sheet to explain the study and informed consent was assumed on completion and submission of the survey responses. A copy of the information sheet and survey based on the

Table 1 Sample profile based on discrete choice experiment design

Imagine you have been diagnosed with asthma. Over the last couple of days you have developed a heavy cough. After showering this morning you noticed you are developing a rash on your upper body which has made you worry about what is going on?

\begin{tabular}{|c|c|c|}
\hline & Option A & Option B \\
\hline Treating healthcare professional & $\begin{array}{l}\text { General practitioner (may not be your } \\
\text { usual GP) }\end{array}$ & $\begin{array}{l}\text { Emergency healthcare professional } \\
\text { (other than a doctor) }\end{array}$ \\
\hline Location & Local clinic & Home \\
\hline Potential cost to you & $\$ 0$ & $\$ 200$ \\
\hline Maximum waiting time & $4 \mathrm{~h}$ & $30 \mathrm{~min}$ \\
\hline Quality of service & $\begin{array}{l}\text { Healthcare professional is easy to } \\
\text { understand, comprehensive treatment } \\
\text { provided with no interruptions }\end{array}$ & $\begin{array}{l}\text { Healthcare professional is not easy } \\
\text { to understand, basic treatment } \\
\text { provided with some interruptions }\end{array}$ \\
\hline Which would you prefer? & $\begin{array}{l}\text { Option A } \\
\square\end{array}$ & $\begin{array}{l}\text { Option B } \\
\square\end{array}$ \\
\hline $\begin{array}{l}\text { If this option was available, would you } \\
\text { take it, or would you delay for } 24 \mathrm{~h} \text { to see }\end{array}$ & $\begin{array}{l}\text { I would take my preferred } \\
\text { option...................... }\end{array}$ & $\square$ \\
\hline $\begin{array}{l}\text { if your condition improves before } \\
\text { accessing care? }\end{array}$ & $\begin{array}{l}\text { I would delay for } 24 \mathrm{~h} \text { to see if my } \\
\text { condition improves before accessing care }\end{array}$ & $\square$ \\
\hline & $\ldots$ & \\
\hline
\end{tabular}

\section{Note:}

Health professional options were emergency department clinician; general practitioner (may not be your usual GP) or an emergency health professional (other than a doctor).

Treatment locations were home, local clinical or hospital.

Potential out-of-pocket expenses were $\$ 0, \$ 50, \$ 100$ or $\$ 200$.

Maximum wait times were $30 \mathrm{~min}, 1 \mathrm{~h}, 2 \mathrm{~h}$ or up to $4 \mathrm{~h}$.

Levels of service quality were; healthcare professional is easy to understand, comprehensive treatment provided with no interruptions; healthcare professional is easy to understand, basic treatment provided with some interruptions; or healthcare professional is not easy to understand, basic treatment provided with some interruptions. 
possible concussion scenario is provided as an online supplementary appendix.

The survey was administered online and consisted of three main components the DCE choice sets, sociodemographic characteristics and attitudinal measures of responsibilities for one's own health. Members of the general public ( $\mathrm{n}=909$ ); 453 participants from QLD and 456 from SA were randomly assigned to complete the main survey version involving a possible concussion. Smaller samples from QLD were assigned to consider the alternative scenarios (rash/asthma—self, $\mathrm{n}=311$; rash/asthma—child, $\mathrm{n}=309$; and the anxiety-related issue, $\mathrm{n}=309$ ).

After being introduced to their respective scenarios, participants were asked to rate the urgency of the situation based on a brief description of triage categories. This rating provided an indicator of their perceived urgency of the situation prior to the consideration of choice sets. Non-parametric tests (Kruskal-Wallis test and Mann-Whitney U tests with Bonferroni corrections for post hoc comparisons of categorical variables) were used to examine if there were significant differences in the public's perceptions of urgency across presenting contexts as well as their intentions to access emergency care alternatives. ${ }^{38} 39$

Preferences for emergency care were analysed in NLOGIT (V.5) ${ }^{40}$ using mixed logit (MXL) regression models. MXL models estimate the effect of the different service attribute levels (independent variables) on choice of service (dependent variable), while allowing service preferences to vary (ie, to be heterogeneous) across the sample. MXL models were generated using 1000 Halton draws, an intelligent simulation method that requires a 10th of the number of draws used with other random approaches. ${ }^{27}$ Treating health professional, location and service quality were specified using effects coding, and the cost and waiting time were coded continuously after confirming that their level effects were linear in preliminary analyses. The resulting patterns of preferences were descriptively compared to identify any variations in intentions to access healthcare or the public's preferences for how this care is delivered. Further, marginal willingness to wait was estimated to quantify trade-offs and used to compare the public's preferences for service delivery across different scenarios. ${ }^{27} 41$ Marginal willingness to wait represents the additional time an individual would be willing to wait in order to gain an improvement in a characteristic of service delivery and is estimated as the ratio between the relevant attribute coefficients in the model. ${ }^{41}{ }^{42}$ Parameters were specified as random and following a normal distribution with CIs calculated using the $\delta$ method, as described by Daly et $a t^{43}$ and software developed by Hess. ${ }^{44}$

\section{RESULTS}

From the 4354 members of the general public who accepted the survey invitation, a total of 2045 people $(46.97 \%)$ met the screening criteria and started the survey. Of these, $89.88 \%$ ( $n=1838$ ) completed the survey to achieve the required sample quotas. The average completion time was $14.37 \mathrm{~min}$, with $99.4 \%$ of participants taking five seconds or longer to choose their preferred option. A total of 1672 participants $(90.96 \%)$ passed the consistency check. In recognition of some concerns about excluding those who fail consistency checks, for example, evidence of lexicographic healthcare preferences, all responses were included in the analysis as a kind of sensitivity analysis employed by Richardson et al. ${ }^{37}$

Although the stratified sample was selected according to quotas to ensure demographic representativeness, comparisons of socioeconomic and health status measures were made with population norms (table 2). Overall the sample appeared to represent the respective state and national population distributions. Notable exceptions included comparatively higher morbidity levels (eg, asthma rates and poorer quality of life), and less culturally diverse and Aboriginal and Torres Strait peoples in the study sample as compared to the general population.

\section{Perceived urgency of presenting problem}

Table 3 presents the triage ratings assigned by participants for each of the presenting scenarios based on a brief description of the categories used in the Australasian Triage Scale where higher scores represent lower levels of urgency. Relatively equal number of participants rated the possible concussion scenario (S1) as a Triage Category 1, 2 or 3. The median score was 2, with an IQR of 1-3, and a mode of 3. For the rash/ asthma-related (self) presentation (S2), the median was 3, IQR 2-4, and mode 4. When the scenario involved the participants' daughter (S3), the median and mode were 3 with the same IQR, providing some indication that more participants considered this a more urgent presentation compared to scenario 2. Notably, the highest level of urgency was assigned to the anxiety-related presentation (S4) with a median score of 2, IQR 1-3.5, and a mode of 1 .

\section{Does presenting context influence uptake of ED services?}

In accordance with participants' differing levels of perceived urgency across the four scenarios, the 'opt out' data (ie, the decision to delay care and monitor the situation) suggested that the degree to which people would take up any service also differed depending on the presenting problem. Table 4 indicates the number of times participants chose to access, rather than delay accessing care. It suggests participants most often elected to access services when considering the rash/asthma-related presentation involving their child (S3) and least frequently for the same problem involving themselves (S2). Interestingly, the pattern of responses for S3 was similar to $\mathrm{S} 1$ (a possible concussion). Kruskal-Wallis results indicated significant differences between presenting contexts $\left(\mathrm{H}_{(3)}=83.65, \mathrm{p}=<0.001\right)$. Using Mann-Whitney tests (with Bonferroni corrections where $\mathrm{p}=0.008$ ), significant 
Table 3 Frequency of triage ratings assigned for presenting scenarios

\begin{tabular}{llll}
\hline Scenario & Sample & Australasian Triage Scale & Frequency \\
\hline (S1) Presentation involving & $(\mathrm{n}=909)$ & 1 (immediately life-threatening) & $233(25.6 \%)$ \\
possible concussion (self) & $(\mathrm{n}=453 \mathrm{QLD})$ & 2 (imminently life-threatening) & $230(25.3 \%)$ \\
& $(\mathrm{n}=456 \mathrm{SA})$ & 3 (potentially life-threatening) & $255(28.1 \%)$ \\
& & 4 (potentially serious) & $153(16.8 \%)$ \\
& & 5 (less urgent) & $38(4.2 \%)$ \\
(S2) Rash/asthma-related & $(\mathrm{n}=311)$ & 1 (immediately life-threatening) & $51(16.4 \%)$ \\
presentation (self) & $(\mathrm{QLD})$ & 2 (imminently life-threatening) & $46(14.8 \%)$ \\
& & 3 (potentially life-threatening) & $61(19.6 \%)$ \\
& & 4 (potentially serious) & $80(25.7 \%)$ \\
(S3) Rash/asthma-related & $(\mathrm{n}=309)$ & 5 (less urgent) & $73(23.5 \%)$ \\
presentation (daughter) & $(\mathrm{QLD})$ & 1 (immediately life-threatening) & $55(17.8 \%)$ \\
& & 2 (imminently life-threatening) & $52(16.8 \%)$ \\
& & 3 (potentially life-threatening) & $85(27.5 \%)$ \\
& & 4 (potentially serious) & $82(26.5 \%)$ \\
(S4) Anxiety related & 5 (less urgent) & $35(11.4 \%)$ \\
presentation (self) & (immediately life-threatening) & $81(26.2 \%)$ \\
& $(\mathrm{n}=309)$ & 2 (imminently life-threatening) & $76(24.6 \%)$ \\
& $(\mathrm{QLD})$ & 3 (potentially life-threatening) & $75(24.3 \%)$ \\
& & 4 (potentially serious) & $51(16.5 \%)$ \\
& & 5 (less urgent) & $26(8.4 \%)$ \\
\hline
\end{tabular}

SA, South Australia; QLD, Queensland.

differences were found between all scenarios except for $\mathrm{S} 1$ and S3 $(\mathrm{z}=-1.39, \mathrm{p}=0.164)$, and S2 and $\mathrm{S} 4 \mathrm{z}=-1.92$, $\mathrm{p}=0.054)$. Thus, while the anxiety scenario was most frequently perceived to be more urgent, participants were most likely to delay accessing care in the context of a possible concussion or rash/asthma-related presentation involving their daughter.

\section{Preferences for emergency care: results of MXL analyses}

MXL models for all four scenarios revealed a good model fit for a choice model ${ }^{27}$ (S1: McFadden pseudo- $\mathrm{R}^{2}=0.371$, AIC $/ \mathrm{N}=1.386$; S2: pseudo- $\mathrm{R}^{2}=0.367$, AIC/N=1.401; S3: pseudo- $\mathrm{R}^{2}=0.395$, AIC/N=1.338; S4: pseudo- $\mathrm{R}^{2}=0.367, \mathrm{AIC} / \mathrm{N}=1.400$ ). The results are presented for each scenario in table 5 . The mean parameters represent the preference weight associated with each attribute level. Positive weights indicate the partworth utility associated with each characteristic and a negative weight the associated disutility. The SD parameters and significance levels indicate the extent of preference heterogeneity around mean parameters across participants.
As indicated in table 5, the constants in each of the models were large, negative and significant suggesting a strong propensity to access any type of emergency care rather than delay care in all scenarios. However, there was marked heterogeneity indicated by the significance of SDs. This heterogeneity and the size and statistical significance of the constant terms suggest the impact of factors beyond the observed service attributes on healthcare choices.

For S1, the results indicate an overall preference to be treated by an ED clinician $(\beta=0.261)$ compared with a GP $(\beta=-0.073, p=<0.001)$ or any emergency health professional other than a doctor $(\beta=-0.188, p=<0.001)$. Participants also preferred treatment at hospital $(\beta=0.119, \quad p=<0.001)$ over treatment at a local clinic $(\beta=-0.091, p=0.002)$ or treatment at home $(\beta=-0.028)$. As expected, lower personal costs $(\beta=-0.019, \mathrm{p}<0.001)$ and shorter wait times were clearly valued $(\beta=-0.012$, $\mathrm{p}<0.001)$, as was comprehensive treatment $(\beta=0.557)$ compared with basic treatment from a clinician who was easy to understand $(\beta=0.156, p<0.001)$ and not easy to understand $(\beta=-0.713, \mathrm{p}<0.001)$. Indeed, the preference weights for service quality suggest that an improvement

Table 4 Number of times participants chose to access care by presenting context

\begin{tabular}{|c|c|c|c|c|c|c|c|}
\hline \multirow[b]{2}{*}{ Scenario } & \multirow[b]{2}{*}{$\mathbf{n}$} & \multirow{2}{*}{$\begin{array}{l}\text { Minimum } \\
\text { (frequency) }\end{array}$} & \multirow{2}{*}{$\begin{array}{l}\text { Maximum } \\
\text { (frequency) }\end{array}$} & \multicolumn{2}{|l|}{ IQRs } & \multirow[b]{2}{*}{$75 \%$} & \multirow[b]{2}{*}{ Mean $( \pm S D)$} \\
\hline & & & & Median & $25 \%$ & & \\
\hline (S1) Possible concussion (self) & 909 & $0(28,3.1 \%)$ & $12(600,66.0 \%)$ & 12 & 10 & 12 & $10.46 \pm 2.98$ \\
\hline (S2) Rash/asthma-related presentation (self) & 311 & $0(24,7.7 \%)$ & $12(139,44.7 \%)$ & 11 & 6 & 12 & $8.78 \pm 3.98$ \\
\hline (S3) Rash/asthma-related presentation (daughter) & 309 & $0(10,3.2 \%)$ & $12(215,69.6 \%)$ & 12 & 11 & 12 & $10.73 \pm 2.77$ \\
\hline (S4) Anxiety related presentation (self) & 309 & $0(16,5.2 \%)$ & $12(161,52.1 \%)$ & 12 & 7 & 12 & $9.28 \pm 3.92$ \\
\hline
\end{tabular}




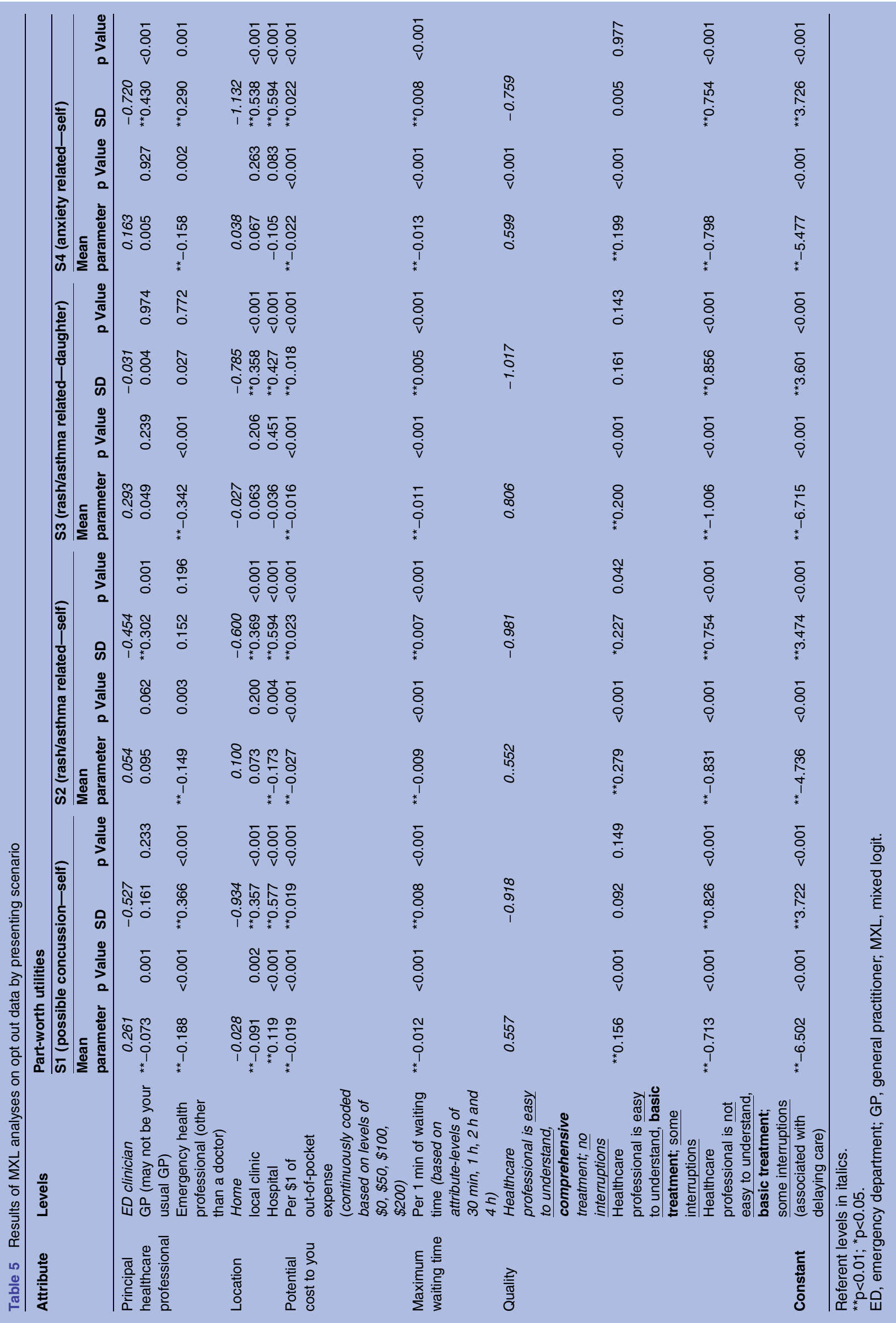


in this service characteristic was relatively more important when compared with marginal improvements in the other attributes in the DCE.

Although treatment by an emergency health professional other than a doctor was the least preferred in all contexts, a different pattern of preferences was observed for S1 compared with the other scenarios. Whereas treatment at hospital was clearly preferred in S1, for each of the remaining scenarios, preferences were strongest for treatment in ambulatory settings, such as a local clinic (S3 and S4) or at home (S2). The different patterns of preferences for treatment location by presenting context are depicted in figure 1. In all four scenarios, there were clear preferences for lower costs (for every dollar of out-of-pocket expense), shorter wait times (for every minute waited) and higher levels of service quality. The marked heterogeneity observed across all contexts and variations observed in both patterns of service uptake and preferences for the different characteristics of care suggest different presenting problems are associated with differences in healthcare choices. Choices differed even when the same problem affected different people (eg, S2 and S3).

\section{Willingness to wait}

In order to directly compare between models, the public's marginal willingness to wait for improvements in service characteristics were estimated. As indicated in table 6 , there was a clear preference to be treated by an ED clinician rather than an emergency healthcare professional in all contexts. The public were willing to wait for an additional $22 \mathrm{~min}$ (95\% CI 9.6 to 34.4; S2) to $60.2 \mathrm{~min}(95 \%$ CI 46.3 to 74.1 ; S3) in order to be treated by an ED clinician rather than another emergency healthcare professional. In the context of a possible concussion, the public were also prepared to wait an additional $27.5 \mathrm{~min}$ (95\% CI 22.3 to 32.7 ) to be treated by an ED Clinician instead of a GP. Participants were willing to wait an additional 29.4 (95\% CI 16.3 to 42.5) minutes to be treated at home rather than in hospital in the context of S2 (rash/asthma), but the opposite effect was observed in relation to willingness to wait estimates for S1, confirming a complex interaction between willingness to wait, preferences for treatment location and the presenting problem. On average, people were willing to wait almost twice as long for every \$1 saved in out-of-pocket expenses for their preferred option when the presenting problems concerned themselves as opposed to their child.

The marginal willingness to wait estimates for tradeoffs in quality varied by level of quality and scenario, ranging from a minimum of an additional 29.5 (95\% CI 17.1 to 41.8 ) minutes for a moderate improvement in quality in S1, to a maximum of 171.8 (95\% CI 136.3 to 207.4) minutes for a large improvement in quality in S3. Participants were willing to wait substantially longer to receive comprehensive care, even in circumstances where one would expect to see a desire for more immediate care. Overall, these results suggest that the public clearly place significant value on high-quality care.

\section{DISCUSSION}

The preferences for emergency care elicited in this study suggest that regardless of cost and waiting time,
Figure 1 Pattern of preferences for treatment location by presenting scenario.

\section{Pattern of preferences for treatment location by presenting scenario}

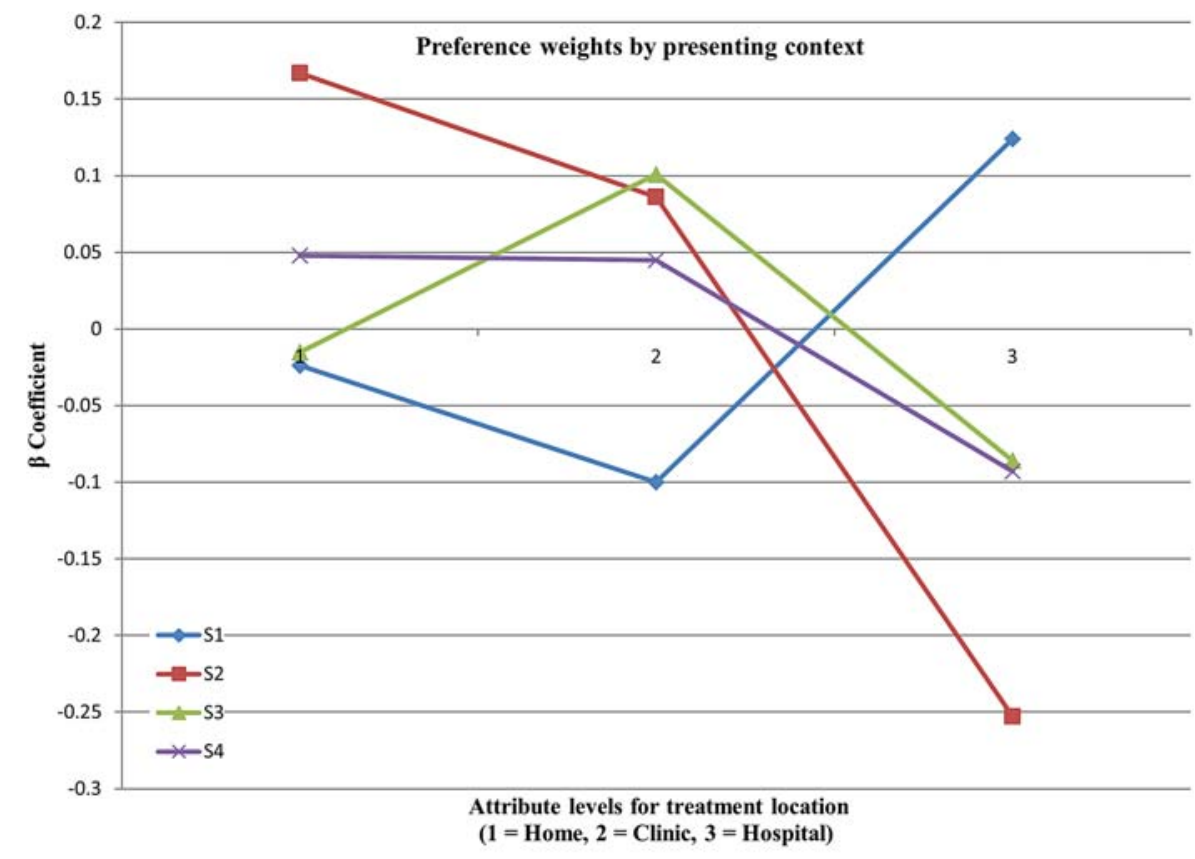

Note: S1 (possible concussion); S2 (rash/asthma related - self); S3 (rash/asthma related-daughter); $S 4$ (anxiety related presentation) 
Table 6 Willingness to wait trade-offs between service characteristics

\begin{tabular}{|c|c|c|c|c|}
\hline \multirow{2}{*}{$\begin{array}{l}\text { Perceived improvement in } \\
\text { service characteristics }\end{array}$} & \multicolumn{4}{|c|}{ Marginal willingness to wait in minutes to gain improvement (with $95 \% \mathrm{Cls}$ ) } \\
\hline & S1 & S2 & S3 & S4 \\
\hline $\begin{array}{l}\text { ED clinician instead of an } \\
\text { emergency health } \\
\text { professional }\end{array}$ & $37.0(30.7$ to 43.4$)$ & $22.0(9.6$ to 34.4$)$ & $60.2(46.3$ to 76.1$)$ & $24.0(15.0$ to 33.1$)$ \\
\hline ED clinician instead of GP & 27.5 (23.3 to 32.7$)$ & & & \\
\hline $\begin{array}{l}\text { Treatment at hospital instead } \\
\text { of home }\end{array}$ & 12.1 (7.0 to 17.2$)$ & & & \\
\hline $\begin{array}{l}\text { Treatment at home instead of } \\
\text { hospital }\end{array}$ & & 29.4 (16.3 to 42.5$)$ & & \\
\hline $\begin{array}{l}\text { Treatment at home instead of } \\
\text { a local clinic }\end{array}$ & $5.2(0.3$ to 10.2$)$ & & & \\
\hline $\begin{array}{l}\text { For every } \$ A 1 \text { reduction in } \\
\text { cost }\end{array}$ & $1.6(1.4$ to 1.7$)$ & 2.9 (2.4 to 3.4$)$ & $1.5(1.3$ to 1.8$)$ & $1.7(1.4$ to 1.9$)$ \\
\hline $\begin{array}{l}\text { Comprehensive care } \\
\text { compared with basic } \\
\text { treatment from a clinician you } \\
\text { can understand with no } \\
\text { interruptions }\end{array}$ & 104.9 (90.5 to 119.3$)$ & $149.2(110.4$ to 188.1$)$ & $171.8(136.3$ to 207.4$)$ & $104.7(82.5$ to 128.0$)$ \\
\hline $\begin{array}{l}\text { Basic treatment from a } \\
\text { clinician you understand } \\
\text { compared with basic } \\
\text { treatment from a clinician you } \\
\text { cannot understand and some } \\
\text { interruptions }\end{array}$ & 33.1 (28.0 to 38.2$)$ & 29.5 (17.1 to 41.8$)$ & 57.5 (45.8 to 69.2$)$ & 30.0 (21.6 to 38.4$)$ \\
\hline
\end{tabular}

the Australian public have a clear preference for treatment by a doctor across all presenting contexts. Although researchers and policymakers have identified a role for models led by nurses and ambulance officers to reduce ED workloads, ${ }^{45}$ the results suggest that there is currently little public support for such innovations in Australia when this is described as care led by 'emergency care practitioners (other than a doctor)'. Consistent with previous results from other countries, ${ }^{11} 24$ there were clear preferences for shorter wait times, higher service quality and support for treatment in proximal service locations including a local GP clinic for 'GP-type' presentations. Indeed, the extraordinary amount of time people were prepared to wait before trading for lower levels of service quality provide further support that this is a primary determinant of healthcare choices. $^{34}$ The findings suggest that the public are clearly adverse to contributing out-of-pocket expenses or receiving treatment from health professionals other than a doctor, suggesting they may be unwilling to support such changes should they be introduced in the future. ${ }^{15} 46$ Nonetheless, these findings provide guidance about how to improve current efforts aimed at reducing wait times and support further investments in ambulatory care alternatives, in particular, for problems involving chronic issues.

Specifically, our analyses have suggested that the presenting context influences preferences for emergency care, both in terms of propensity to access emergency care and preferences for the different characteristics of service options. Differences were observed not only for different conditions, but also according to who was being treated (ie, when the problem affected their daughter rather than themselves). These findings are to be expected given the literature on social constructions of childhood and heightened notions of vulnerability, ${ }^{47} 48$ which in part have led to the establishment of dedicated paediatric ED and/or treatment areas within ED. ${ }^{6} 7$ Indeed, triage categories reflect an urgency rather than a complexity scale and clinicians may also assign different urgency ratings to similar presenting problems in different patients. ${ }^{12}$ Further, presentations involving skin rashes are also recognised as being particularly challenging to assess. ${ }^{49}$ However, the urgency ratings assigned by participants, including for the anxiety-related scenario, also support the assertion that the public understand health emergencies differently to that outlined in triage guidelines ${ }^{4}$ and may give more weight to psychosocial considerations rather than just physiological metrics or threats to life. ${ }^{22}$ The implication of these findings for health policy and decision-makers is that although the public may have differing views about how quickly non-life-threatening problems need to be treated, they also recognise that different problems may be treated in different settings, even if they still want to be treated urgently, as evidenced in the anxiety-related scenario. 
Our results are similar to findings from a recent Hong Kong study, ${ }^{11}$ demonstrating the need to further examine how patient perceptions of presenting problems drive healthcare decision-making. Although recent international studies have suggested that more than half of all visits to ED are classified as non-emergencies, the availability of alternative ambulatory care services has done little to reduce demand. ${ }^{2650}$ Our study sheds light on this persistent problem, demonstrating clear preferences for higher levels of service quality delivered by doctors (and emergency specialists in the case of suspected concussion). The preferences elicited for the 'GP-type scenarios' suggest the Australian public generally prefer to be treated at their local GP clinic in these circumstances. However, other doctor-led models, including integration of GP clinics within ED, extended hours of GP cooperatives and in-home care, ${ }^{11} 45$ and redesigning patient flow processes (eg, fast-track streams for chronic-diseaserelated issues) ${ }^{3} 56121351$ could gain public acceptance in the future.

The levels of preference heterogeneity observed across all DCE scenarios raise the need for further analyses and exploration of the public's preferences. Although there was a different pattern of preferences evident for accessing care when presentations involved new concerns and possible chronic problems compared with an acute injury, the heterogeneity observed may also help explain why a substantial proportion of ED presentations continue to be considered 'inappropriate'11 225052 even when ambulatory alternatives are available. ${ }^{26}$ It is likely that a range of situational or sociodemographic factors may impact preferences ${ }^{1}$ and these will be explored in future analyses.

The moderate response rate, although comparable to other internet and paper-based choice studies, ${ }^{30} 5354$ and the under-representation of culturally diverse participants in our sample is noteworthy. Sample bias may have originated from the use of a panel recruitment company and internet-administered surveys. ${ }^{55}$ Whereas future researchers would benefit from undertaking their formative qualitative research with consumer representatives, the initial focus groups used to design the DCE survey largely comprised health professionals. Another limitation of our study was that the description of each of the hypothetical scenarios was brief, using simple everyday language which may have left too much opportunity for participants to infer missing information. Although this was a deliberate strategy, it is acknowledged that our brief description of presenting context may not have been as useful as anticipated. Nevertheless, the research was exploratory and many of the challenges are overshadowed by our large relatively representative sample, and the use of multiple scenarios and systematic comparison of different attributes. Although caution should be applied in generalising the results of this study, findings suggest future research should examine other variations of the patient, nature and time of presenting problems as well as models of care led by other health professionals. The public's apparent aversion to non-doctor led care may have been influenced by our framing of this choice as 'other than a doctor'. This change was made to improve clarity in response to feedback from the pilot study, however, may have resulted in this being perceived as a loss or 'substandard' choice. ${ }^{56}$ The findings also suggest the need to investigate the influence of other individual factors on healthcare decisionmaking. Researchers and decision-makers may then be able to isolate the preferences of specific groups, such as high service users or people found to be less likely to delay care to inform demand management strategies.

\section{CONCLUSION}

Overall, the findings from this study suggest that the Australian public do not support being treated by an emergency health practitioner other than a doctor, irrespective of the presenting problem, or reductions in cost or wait times. This conclusion appears to be supported by the high value the public have placed on service quality. Results do, however, provide support for reforms focusing on providing greater access to GP-based ambulatory care as well as efforts to reduce wait times without increasing cost. Although the literature is mixed about the degree to which ambulatory care alternatives reduce pressures on ED, our findings provide evidence that citizens do make different decisions about when to access emergency care according to their presenting situation, as reflected in the different pattern of choices. They also suggest different presenting contexts including when the same problem affects different people and influences their choices. Indeed, when the presenting problems affected a child these were perceived as more urgent, led to higher rates of service uptake and also marked differences in the public's willingness to wait before making trade-offs in care. Future investigations are needed to clarify how these contextual issues and other differentiating factors influence these decisionmaking processes. This type of knowledge will assist us not only to better understand the public's preferences for accessing services but, more broadly, also to develop and target specific demand management strategies for emergency care services and related primary healthcare initiatives

\section{Author affiliations}

${ }^{1}$ School of Medicine, Population and Social Health Research Program, Menzies Health Institute Queensland, Griffith University, Meadowbrook, Queensland, Australia

${ }^{2}$ Faculty of Health and Behavioural Sciences, School of Pharmacy, The University of Queensland, St Lucia, Queensland, Australia

${ }^{3}$ Centre of National Research on Disability and Rehabilitation, Population and Social Health Research Program, Menzies Health Institute Queensland, Griffith University, Meadowbrook, Queensland, Australia

${ }^{4}$ Flinders Health Economics Group, School of Medicine, Flinders University, Adelaide, South Australia, Australia

${ }^{5}$ Menzies Centre for Health Policy, School of Public Health, University of Sydney, Sydney, New South Wales, Australia

${ }^{6}$ Division of Health and Social Care Research, King's College School of Medicine, London, UK 
${ }^{7}$ Centre for Applied Health Economics, Population and Social Health Research Program, Menzies Health Institute Queensland, Griffith University, Meadowbrook, Queensland, Australia

Acknowledgements The authors are grateful for the in-kind support from the funding organisations and from other partner organisations, including Queensland University of Technology, University of Sydney, Flinders University, and the National Institute for Health and Care Excellence (NICE).

Contributors All authors contributed to the research design. The DCE was developed by JAW, PH, JR, EK and PAS. PH and JAW led data analysis. All authors reviewed and approved the final manuscript led by $\mathrm{PH}$.

Funding This work was supported through an Australian Research Council Linkage Project, grant number LP100200446. Additional financial contributions were received from state health authorities in Queensland and South Australia.

Competing interests None.

Ethics approval Griffith University Human Research Ethics Committee (Reference Number: MED/10/12/HREC).

Provenance and peer review Not commissioned; externally peer reviewed.

Data sharing statement Requests for results of preliminary analyses, coding and other information can be directed to the corresponding author.

Open Access This is an Open Access article distributed in accordance with the Creative Commons Attribution Non Commercial (CC BY-NC 4.0) license, which permits others to distribute, remix, adapt, build upon this work noncommercially, and license their derivative works on different terms, provided the original work is properly cited and the use is non-commercial. See: http:// creativecommons.org/licenses/by-nc/4.0/

\section{REFERENCES}

1. Green J, Dawber J, Masso M, et al. Emergency department waiting times: do the raw data tell the whole story? Aust Health Rev 2014;38:65-9.

2. Moskop JC, Sklar DP, Geiderman JM, et al. Emergency department crowding, part 1-concept, causes, and moral consequences. Ann Emerg Med 2009;53:605-11.

3. Forero R, Hillman KM, McCarthy S, et al. Access block and ED overcrowding: short report. Emerg Med Australas 2010;22:119-35.

4. Australasian College for Emergency Medicine. Policy on the Australasian Triage Scale. Melbourne: 2006 July, 2013.

5. Fitzgerald G, Ashby R. National Health and Hospital Network for Australia's future: implications for emergency medicine. Emerg Med Australas 2010;22:384-90. [Epub ahead of print 3 Nov 2010].

6. Kim BB, Delbridge TR, Kendrick DB. Improving process quality for pediatric emergency department. Int J Health Care Qual Assur 2014;27:336-46.

7. Hostetler MA, Mace S, Brown K, et al. Emergency department overcrowding and children. Pediatr Emerg Care 2007;23:507-15.

8. Hadorn DC. The role of public values in setting health care priorities. Soc Sci Med 1991;32:773-81.

9. Ang JB. The determinants of health care expenditure in Australia. Appl Econ Lett 2010;17:639-44

10. Cunningham PJ. What accounts for differences in the use of hospital emergency departments across U.S. communities? Health Aff 2006;25:w324-36.

11. Leung GM, Chan SSC, Chua PYK, et al. Using conjoint analysis to assess patients' preferences when visiting emergency departments in Hong Kong. Acad Emerg Med 2001;8:894-8.

12. Nagree $Y$, Gosbell A, McCarthy $S$, et al. Determining the true burden of general practice patients in the emergency department: getting closer. Emerg Med Australas 2013;25:487-90.

13. Nagree $Y$, Cameron $P$, Gosbell $A$, et al. Telephone triage is not the answer to ED overcrowding. Emerg Med Australas 2012;24:123-6.

14. Burke GR, Rebgetz L. Qld aims to free up hospital emergency departments from treating minor ailments. ABC News 2014.

15. Medew J, Willingham R. Federal Budget: doctors vow to fight hospitals introducing co-payment for emergency department care. The Sydney Morning Herald: Business Day 2014

16. Knox I. A submission to the National Health and Hospitals Reform Commission on the role of private hospital emergency departments with the national health system: prepared on behalf of the
Australasian College for Emergency Medicine. Australasian College for Emergency Medicine, 2008.

17. Skinner CA. Inside the emergency department. Med J Aust 2007;187:634-5.

18. Fatovich DM, Nagree $Y$, Sprivulis P. Access block causes emergency department overcrowding and ambulance diversion in Perth, Western Australia. Emerg Med J 2005;22:351-4.

19. Mason S, Weber EJ, Coster J, et al. Time patients spend in the emergency department: England's 4-hour rule-a case of hitting the target but missing the point? Ann Emerg Med 2012;59:341-9.

20. Bryan S, Dolan P. Discrete choice experiments in health economics. For better or for worse? Eur J Health Econ 2004;5:199-202.

21. Scuffham PA, Ratcliffe J, Kendall E, et al. Engaging the public in healthcare decision-making: quantifying preferences for healthcare through citizens' juries. BMJ Open 2014;4:e005437.

22. Morgans A, Burgess SJ. What is a health emergency? The difference in definition and understanding between patients and health professionals. Aust Health Rev 2011;35:284-9.

23. Arendts G, Howard K, Rose JM. Allocation decisions and patient preferences in emergency medicine. Emerg Med J 2011;28:1051-4.

24. Gerard K, Lattimer V, Turnbull J, et al. Reviewing emergency care systems 2: measuring patient preferences using a discrete choice experiment. Emerg Med J 2004;21:692-7.

25. San Miguel F, Ryan M, Scott A. Are preferences stable? The case of health care. J Econ Behav Organ 2002;48:1-14

26. Chan CL, Lin W, Yang NP, et al. The association between the availability of ambulatory care and non-emergency treatment in emergency medicine departments: a comprehensive and nationwide validation. Health Policy 2013;110:271-9.

27. Hensher D, Rose JM, Greene WH. Applied choice analysis: a primer. Cambridge: Cambridge University Press, 2005.

28. Rubin G, Bate A, George A, et al. Preferences for access to the GP: a discrete choice experiment. Br J Gen Pract 2006;56:743-8.

29. Cheraghi-Sobi S, Hole AR, Mead N, et al. What patients want from primary care consultations: a discrete choice experiment to identify patient's priorities. Ann Fam Med 2008;6:107-15.

30. Hjelmgren J, Anell A. Population preferences and choice of primary care models: a discrete choice experiment in Sweden. Health Policy 2007;83:314-22.

31. Scott A, Watson SM, Ross S. Eliciting preferences of the community for out of hours care provided by general practitioners: a stated preference discrete choice experiment. Soc Sci Med 2003;56:803-14.

32. Johnson FR, Lanscar E, Marshall D, et al. Constructing experimental designs for choice-format conjoint analysis studies: report of the ISPOR conjoint analysis experimental design taskforce. Value Health 2012;16:3-13

33. Bridges JF, Hauber AB, Marshall D, et al. Conjoint analysis applications in health-a checklist: a report of the ISPOR Good Research Practices for Conjoint Analysis Task Force. Value Health 2011;14:403-13.

34. Kobayashi M, Mano T, Yamauchi K. Patients' preference on selecting a medical institution. Int $J$ Health Care Qual Assur 2013;26:341-52.

35. Lancsar E, Louviere J. Conducting discrete choice experiments to inform healthcare decision making: a user's guide. Pharmacoeconomics 2008;26:661-77.

36. Blake DF, Dissanayake DB, Hay RM, et al. 'Did not waits': a regional Australian emergency department experience. Emerg Med Australas 2014;26:145-52.

37. Richardson G, Bojke C, Kennedy A, et al. What outcomes are important to patients with long term conditions? A discrete choice experiment. Value Health 2009;12:331-9.

38. Agresti A. An introduction to categorical data analysis. 2nd edn Hoboken: John Wiley \& Sons, 2007.

39. Pallant J. SPSS survival guide: a step by step guide to data analysis using IBM SPSS. 5th edn. Sydney: Allen \& Unwin, 2013.

40. Rose JM, Collins AT, Bliemer MCJ, et al. NGENE. V.1.1.1 ed2012.

41. Payne K, Roberts SA, Elliot RA, et al. Valuing pharmacogenetic testing services: a comparison of patients' and health care professionals' preferences. Value Health 2011;14:121-34.

42. Lancsar E, Louviere J, Flynn T. Several methods to investigate relative attribute impact in stated preference experiments. Soc Sci Med 2007;64:1738-53.

43. Daly A, Hess S, de Jong G. Calculating errors for measures derived from choice modelling estimates. Transp Res B 2012;46:333-41.

44. Hess S. Spreadsheet tool for the calculation of standard errors for differences, sums, ratios and products of coefficients. Excel ed 2012. http://www.stephanehess.me.uk/software.htm

45. Fry MM. A systematic review of the impact of afterhours care models on emergency departments, ambulance and general practice services. Australas Emerg Nurs J 2011;14:217-25. 
46. O'Hara R, O'Keeffe C, Mason S, et al. Quality and safety of care provided by emergency care practitioners. Emerg Med $J$ 2012;21:273-4.

47. Lowe RJ. Children deconstructing childhood. Child Soc 2012:26:269-79.

48. Smith R. A universal child? Basingstoke: Palgrave Macmillan, 2010.

49. Thompson PA, Langemo D, Hanson D, et al. Assessing skin rashes. Nursing 2008;38:59.

50. Tsai JC, Liang YW, Pearson WS. Utilization of emergency department in patients with non-urgent medical problems: patient preference and emergency department convenience. J Formos Med Assoc 2010;109:533-42.

51. Grouse Al, Bishop RO, Gerlach L, et al. A stream for complex, ambulant patients reduces crowding in an emergency department. Emerg Med Australas 2014;26:164-9.

52. Krug SE. Access and use of emergency services: inappropriate use versus unmet need. Clin Pediatr Emerg Med 1999;1:35-44.

53. Whitty JA, Scuffham PA, Rundle-Thiele SR. Public and decision maker stated preferences for pharmaceutical subsidy decisions: a pilot study. Appl Health Econ Health Policy 2011;9:73-9.
54. Bech M, Kjaer T, Lauridsen J. Does the number of choice sets matter? Results from a web survey applying a discrete choice experiment. Health Econ 2011;20:273-86.

55. Bell J, Huber J, Viscusi WK. Survey mode effects on valuation of environmental goods. Int J Environ Res Public Health 2011;8:1222-43.

56. Kahneman D. Thinking, fast and slow. London: Penguin Group, 2011.

57. Australian Bureau of Statistics. 2011 Census Quickstats. 2012. http://www.censusdata.abs.gov.au/census_services/getproduct/ census/2011/quickstat/3RQLD?opendocument\& navpos $=220$ (accessed 29 Jun 2012).

58. Hawthorne G, Korn S, Richardson J. Population norms for the AQoL derived from the 2007 Australian National Survey of Mental Health and Wellbeing. Aust N Z J Public Health 2013;37:7-16.

59. Queensland Health. The health of Queenslanders 2012 advancing good health: fourth report of the chief health officer Queensland. Brisbane: Queensland Government, 2012.

60. Australian Bureau of Statistics. Health services: patient experiences in Australia. Canberra: ABS, 2009.

61. AlHW. Health Workforce. 2013. http://www.aihw.gov.au/healthworkforce/ 